\title{
International collaboration between Latin American universities towards educational innovation in engineering: Case study
}

\author{
M. Ileana Ruiz-Cantisani \\ Tecnológico de Monterrey \\ miruiz@tec.mx
}

\author{
Vianney Lara-Prieto \\ Tecnológico de Monterrey \\ vianney.lara@tec.mx
}

\author{
Claudio Mourgues \\ Pontificia Universidad Católica de \\ Chile \\ cmourgue@ing.puc.cl
}

\author{
Fabiola del C. Lima-Sagui \\ Tecnológico de Monterrey \\ fabiola.lima@tec.mx
}

\author{
Luis A. Pinzón-Salcedo \\ Universidad de los Andes, \\ lpinzon@uniandes.edu.co
}

\begin{abstract}
Collaboration between universities has become a driving force to develop and promote a culture of educational innovation with technology and innovative pedagogical strategies. This research exposes the case study of three Latin American universities that seek to identify problems or educational situations to be addressed and developed innovation proposals in exploring in the solution, through an international collaborative initiative with teams of research professors focused on developing educational innovations that inspire and train future professionals. The case study methodology has three phases: 1) case design, 2) case description and 3) case evaluation. The case is analyzed from two perspectives: in ternational initiative managers and the faculty who collaborate in research with their colleagues from other universities using the funds for the awarded projects. The challenges presented are many: from the generation of faculty teams, communication and collaboration at a distance, differences in structure and schedules between universities, and more. However, the benefits have been equally many as synergies have been created not only between universities and within the institutions themselves, but also with companies; another benefit is the learning and knowledge generated by the collaboration is impacting the students, who are the ultimate goal and inspiration of all academic endeavors.
\end{abstract}

\section{CCS CONCEPTS}

- applied computing; • education; • collaborative learning;

\section{KEYWORDS}

International Collaboration, Educational Innovation, Higher Education

\section{ACM Reference Format:}

M. Ileana Ruiz-Cantisani, Vianney Lara-Prieto, Claudio Mourgues, Fabiola del C. Lima-Sagui, and Luis A. Pinzón-Salcedo. 2021. International collaboration between Latin American universities towards educational

Permission to make digital or hard copies of all or part of this work for personal or classroom use is granted without fee provided that copies are not made or distributed for profit or commercial advantage and that copies bear this notice and the full citation on the first page. Copyrights for components of this work owned by others than ACM must be honored. Abstracting with credit is permitted. To copy otherwise, or republish, to post on servers or to redistribute to lists, requires prior specific permission and/or a fee. Request permissions from permissions@acm.org.

ICDTE 2021, September 15-17, 2021, Busan, Republic of Korea

(c) 2021 Association for Computing Machinery.

ACM ISBN 978-1-4503-8499-5/21/09..\$15.00

https://doi.org/10.1145/3488466.3488478 innovation in engineering: Case study. In 2021 5th International Conference on Digital Technology in Education (ICDTE 2021), September 1517, 2021, Busan, Republic of Korea. ACM, New York, NY, USA, 7 pages. https://doi.org/10.1145/3488466.3488478

\section{INTRODUCTION}

Considering the technological and cultural changes currently seen all over the world, universities are relevant and essential players to ensure the adaptation of knowledge and practices within the university curriculum. Universities must prepare students to be able to face the current world challenges. One important skill to be developed is the use of information and communication technology. This millennium generation of students has a different learning style and they are more effective when they perform multisensorial activities [1].

Incorporation of grand challenges into higher education can facilitate the development of collaborative problem-solving skills while providing relevant and practical opportunities to experience the dynamics involved in real-world work [2]. These challenges that imply collaboration considering cultures, customs, politics, common and different problems at the same time, confronted with a more complex environment due to a pandemic that affects humanity, are the same that students and professors face when developing their academic activity. On the other hand, the reality of Latin countries also shares complex problems and needs to close gaps through quality education, with the use of technology that inspires students to commit themselves to their education and their discipline, allowing them to generate future innovations that improve the quality of life in their different countries.

In this research, the use of study case aims to share the collaborative initiative between three Latin American universities in the search to impact education and reduce the gap in society, through research and educational innovation with inter-university teams of professors. It is outlined by three educational institutions which integrate the International Collaborative Initiative: University 1 (Tecnológico de Monterrey, México), University 2 (Pontificia Universidad Católica de Chile, Chile) and University 3 (Universidad de los Andes, Colombia). The International Collaborative Initiative is an international alliance between three of some of the top ranked universities in Latin America. The main objective of the alliance is to work together to tackle the main challenges of their region and aim for a better future for all. This work focuses on the research on educational innovation among the three universities, with the 
aim of exploring an institutional collaboration strategy to increase the innovation in education through the analysis of a case study. This article will guide the reader through literature about international collaboration and educational innovation, then explains the methodology, initiative design: study case, discussion, results, and conclusions.

The development of this project involves the development of the case study in its different stages focused on the implementation of this international collaboration to foster innovation in education, from the design stage of the collaboration agreement to the implementation of the awarded educational research projects, sharing in particular the experience of the faculty of one of the awarded projects as one of the perspectives of analysis, in addition to the perspective of the strategic lead group that manages the international initiative. Regarding the application of the case, the whole process was carried out, while has impacted the development and implementation plan of the awarded projects, generating a delay of some months. This delay caused by SARS-CoV-2, forced a change in the work plan initially outlined by the universities. It is worthwhile to mention that the study case applied, has been carried out with learning and adjustments, encouraging collaboration through digital media resources.

\section{LITERATURE REVIEW}

\subsection{International Collaboration}

International collaboration between universities usually involves the exchange of students, sharing best practices in teaching and conducting research together. In terms of research, there is a bigger impact when working with an international team. An analysis of 25 million publications showed that research that results from international collaboration has more visibility and is cited more frequently by other publications [3]. There are many reasons to get out of the comfort zone and engage in international partnerships with other universities. Wagner [4] suggests the five major motivations for international collaborations are: (1) to increase visibility, (2) to share project costs, (3) to gain or share access to an expensive resource, (4) to achieve greater leverage by sharing data, and (5) to increase creativity by exchanging ideas.

A study by White [5] indicates that the percentage of worldwide Science and Engineering articles produced with international collaboration, i.e. by authors from universities and research institutions from two or more countries, rose from $17 \%$ to $23 \%$ between 2008 and 2018. Additionally, research publications produced through international partnerships are more highly cited. This is explained by the audience effect, since their reader community is larger, but also by the virtuous cycle in which their reputation is enhanced [6].

Research by Valk and Kratovitš [7] list among the main factors influencing collaboration the following: the existence of common interests, trust, involvement mechanisms, role of personality, professionalism, and organizational culture. A successful collaboration requires commitment and communication from all the involved parts. It also requires a well-defined collaboration framework with clear goals, roles, and commitments [8]. Scientists recognize the importance of scientific international partnerships. However, they also admit that it requires an extra effort, getting out of the comfort zone and working against the barriers that impede such collaboration. These barriers include political, logistical and cultural factors, such as lack of funding for international work, restrictions on material and data sharing, differences in academic standards, bias against scholars from emerging countries, language differences, research ethics, academic calendars, time zone differences, among others [9].

\subsection{Educational Innovation}

Universities have traditionally worked to prepare undergraduate students to be ready to face the real world. However, nowadays we are constantly reminded that our graduates will join the workforce in jobs that do not yet exist, applying technologies that have not yet been invented, and solving problems that we are not yet aware of. The challenge in higher education worldwide is: How can we better educate our students in a volatile, uncertain, complex and ambiguous world? [10]. Educational innovation looks into addressing this challenge by applying innovative pedagogical strategies such as project-based, problem-based, challenge-based, experiential, and collaborative learning, integrating educational technology as part of the educational process, and aiming for a more personalized education [11]. The drive of the Fourth Industrial Revolution and the pressure of industry stakeholders to have a workforce with the required set of skills have translated into the higher education institutions to avoid obsolescence in their academic programs [12]. Substantial changes to the science and technology curriculum are required to allow students to develop skills integrating the new technologies of Industry 4.0 [13]. Some examples of these new technologies are: 3D printing, virtual and augmented reality, robotics, artificial intelligence, data science, Internet of Things, and cloud computing. There are several cases in literature that show some efforts done applying challenge-based learning approaches with educational technology towards educational innovation in engineering education [14-16].

This project presents the case study of a strategy of international collaboration between three large private Latin American universities having as main objective increasing the educational innovation at their institutions. The case study involves the partnership of a group of professors with different engineering backgrounds joining efforts to enhance their students' learning experience. The study presents the context in which this inter-university alliance takes place, proposes a collaboration framework, and evaluates this framework through interviews with the strategic team and the experience of the professors participating in the research team. Finally, the key takeaways are highlighted hoping to motivate more universities to engage in this kind of collaboration.

\section{METHODOLOGY}

The case study as a research methodology is frequently used when one considers qualitative research methods. The case study method was selected in order to build and understand the reality of the implementation of an initiative that impacts universities in Latin America in order to contribute to educational research [17, 18]. This case study describes the development of the research project through a strategic linkage between the best ranked universities in Latin America, with institutional funds, and faculty teams. The 
Table 1: Universities' Characteristics [21]

\begin{tabular}{llll}
\hline Topics & University 1 & University 2 & University 3 \\
\hline Country & México & Chile & Colombia \\
National Locations & 26 campuses & 5 campuses & 2 campuses \\
Undergraduate student & 57,000 & 27,895 & 14,337 \\
population & & & 3,900 \\
Graduate student population & 7,000 & 4,559 & 1,216 \\
Faculty (Fulltime) & 2,396 & 2,343 & 340 \\
International students & 1,621 & 1,063 & 164 \\
International Faculty & 986 & 235 & January - May \\
Academic Calendar & February - June, & March - July & August - December \\
& August - December & August - December & High \\
Research output & High & Very High & 1948 \\
Foundation year & 1943 & 1888 & \\
\hline
\end{tabular}

process is developed in phases, and the experience of a year of collaborative work up to the resource design phase is presented. The phases are: 1) case design, 2) case description: integration of the call, development of the proposal, inter-university planning session, definition of the resources, development of the extended realities resources, next steps, and 3) case evaluation through interviews with the strategic team and the experience of the research team. The case study allows to generate an understanding among researchers about educational practices that are carried out with academic rigor [19].

The case design phase [20] integrates the elements that precede the situation that the current environment demands, the background of the universities themselves that lead them to encourage these initiatives, the positions of universities in Latin America, the definition of the implementation of the experience from the perspective of the faculty, as well as an evaluation from the main perspectives of the case: the managerial level that creates, manages and promotes this initiative, as well as from the experience of the faculty as a research team.

To understand the impact of this collaborative initiative among Latin American universities, some of the main characteristics of the three partner universities in promoting this partnership in educational innovation with funds are presented (see Table 1).

The next phase is the case description, each of the stages of the initiative are developed, explaining the elements as the steps of the process, the stakeholders involved, and the factors that influence its implementation; all of the previous elements for each of the aforementioned stages : a) integration of the call, b) development of the proposal, c) inter-university research team planning session, d) definition of the resources, e) development of projects related with educational innovation resources, and f) next steps.

The last phase is the case evaluation. At this stage, semistructured interviews are used with the strategic leaders of the 3 universities that have designed, implemented and monitored the international collaboration initiative with funds from the institutions and directed to professors from all faculties. Semi-structured interviews can be a flexible guide with an interactive approach to deepen the research topic in question, which is why in this phase we proceeded to use this instrument for the perspective of the strategic team; the triangularization of actors, instruments and interviews is important to consider for the evaluation of the case study [17, 22] Only one implementation cycle has been carried out with lessons learned that have allowed the redesign of the second call launched this year. The experience of the research team is compared with the reflections made individually and as a team, as well as the participations in events where the experience of participation is shared as well as the progress achieved so far.

The next section presents the study case from the perspective of the institutions and from one of the awarded projects.

\section{INITIATIVE DESIGN \& IMPLEMENTATION: STUDY CASE}

Local Funds Call is an initiative of the University 1 that "supports the development of innovative ideas in the training process of students. Its purpose is to promote research in educational innovation as a means for the professional development of faculty, the improvement of their teaching practice and the construction of the future of education". [23] Through the experience of several years, since 2017 began conversations between 3 internationally ranked universities in Latin America, which seek to capitalize on the experience in research, particularly in educational research, in the search to close gaps with the support of educational technology and innovation. The international collaboration agreement was signed in 2018, and the first call for proposals was launched in the summer of 2019 [24 ], with funding from the 3 universities. A team was appointed to design, manage and evaluate the impact of the call, with a representative from each university.

The first call for proposals consisted of two stages: A) The first individual, where professors from the different universities made research proposals in educational innovation, in this phase 206 proposals were received from the 3 universities. B) In the second stage, the integration of proposals with professors from the 3 universities was requested (at least 1 professor from each university), in this phase 22 proposals were received. For the integration of these proposals, communication between professors of the 3 universities is developed to align common interests in the topics of research and educational innovation. 
In November 2019, the results of the call were communicated, with 3 teams of researchers selected as awarded projects:

- Augmented reality to enhance anatomy learning. (Medicine School)

- Virtual professional portfolio (Medicine School)

- Extended reality to apply knowledge in the work environment (School of Engineering \& Sciences). This is the documented case.

Once the projects to which the funds will be allocated are communicated, two actions trigger the planning process of each research team: the request for a work plan with progress and final deliverables, and the detailed allocation of the budget by university. In the case that refers us to this research, it is the project that seeks to diagnose the level of "engagement" of students in relation to their discipline through the use of extended realities, generating open access resources to the 3 universities in the engineering disciplines. This research is preceded by a previous one, whose objective was to design industrial environments using virtual reality [14-16, 25]. The first planning meeting of the team of professors of the projects takes place in December 2019, with a second meeting in January 2020 , to send its first deliverable in the first months of the year. The definition of the resources per university, the general project planning, and the local project planning are the main deliverables.

During 2020, planning and project progress meetings were held, which were delayed due to the impact of the pandemic and the priority of transforming $100 \%$ of face-to-face classes into flexible digital classes. This meant a delay of at least 4 months, to be reactivated around September 2020.

During the planning \& implementation stage, it was considered that during the February-June 2020 semester, the educational innovation resources would be defined and developed, as well as the instruments to evaluate their impact on students. By the AugustDecember 2020 semester, they would be implemented in the classes at each university with the evaluation instruments; during this period, visits between universities were contemplated to observe the implementation in each of the institutions. And finally, in the February-June 2021 semester, the results of the projects would be documented and published.

Due to the delay caused by the pandemic situation, the implementation of the project plan is delayed by one semester (the same situation is repeated with the other two projects selected as finalists). Therefore, we are currently in the implementation phase of the academic resources, using extended realities, designed to innovate in engineering education and evaluate the impact on student engagement.

In order to take advantage of the experience of this first cycle of the inter-university linkage effort to promote research and educational innovation with funds from the 3 universities, it was decided to launch the second call for proposals in March 2021. In the meantime, there will be an opportunity to share the experiences of the 3 awarded projects of the first call 2019, through online sessions, and participation in events of the institutions.

Each phase is shown in Fig. 1, considering the design of the case, and the perspectives of the Strategic Managers Team and from the perspective of the faculty research of one of the 3 awarded projects.

\section{DISCUSSION \& RESULTS}

The results are presented from a macro and a micro perspective. The macro perspective refers to the assessment made by the strategic leaders of each institution while the micro perspective is made by the execution team of one the awarded projects (i.e, Extended reality to apply knowledge in the work environment).

\subsection{Macro perspective}

The strategic leaders were interviewed separately and their answers were compared in order to obtain a more complete perspective. Table 2 summarizes the main takeaways from the interviews.

\subsection{Micro perspective}

This assessment is organized in three main topics: challenges, learnings, and success. And it is made by the execution team of one the awarded projects.

The Collaboration challenges are:

- The team integration with professors from the three universities. Each institution has its own organizational structure, research culture and different academic calendars [9]. Sharing topics of mutual interest, the approach to these topics, and the understanding of the initiative were part of the elements that impacted the process $[4,7]$.

- Different educational disciplines and subjects: the researchers from both the University 1 and University 3 came from the industrial engineering field, but they were focused on different educational subjects, which led to the development of different educational experiences. On the other hand, the researcher from University 2 came from the civil engineering field, which also presented different educational needs. These differences presented the challenge of creating a framework that could allow a consistent comparison between the extended reality experiences that each researcher was developing.

- Physical and cultural distance: this distance not only applied to the researchers, affecting their communication, coordination, and collaboration; but also, to the research subjects, as the students who were going to participate in the experiences, had to be interviewed and assessed using instruments that did not introduce cultural biases.

- Pandemic: the extended reality experiences developed for this project required the access to project sites, production lines, and technology that were not easily available due to the sanitary constraints imposed by the COVID-19 pandemic.

The Learnings of the whole experience until now are:

- Basic common ground despite subject and context differences: facing the challenge of different educational disciplines and subjects, the research team found commonalities that helped not only to develop consistent assessment instruments for this project, but also provided insights in their general educational practices, beyond the scope of this research project.

- Collaborative work structures: In addition to the team of leading professors with representatives from the 3 universities, work teams of different nature were integrated in each 

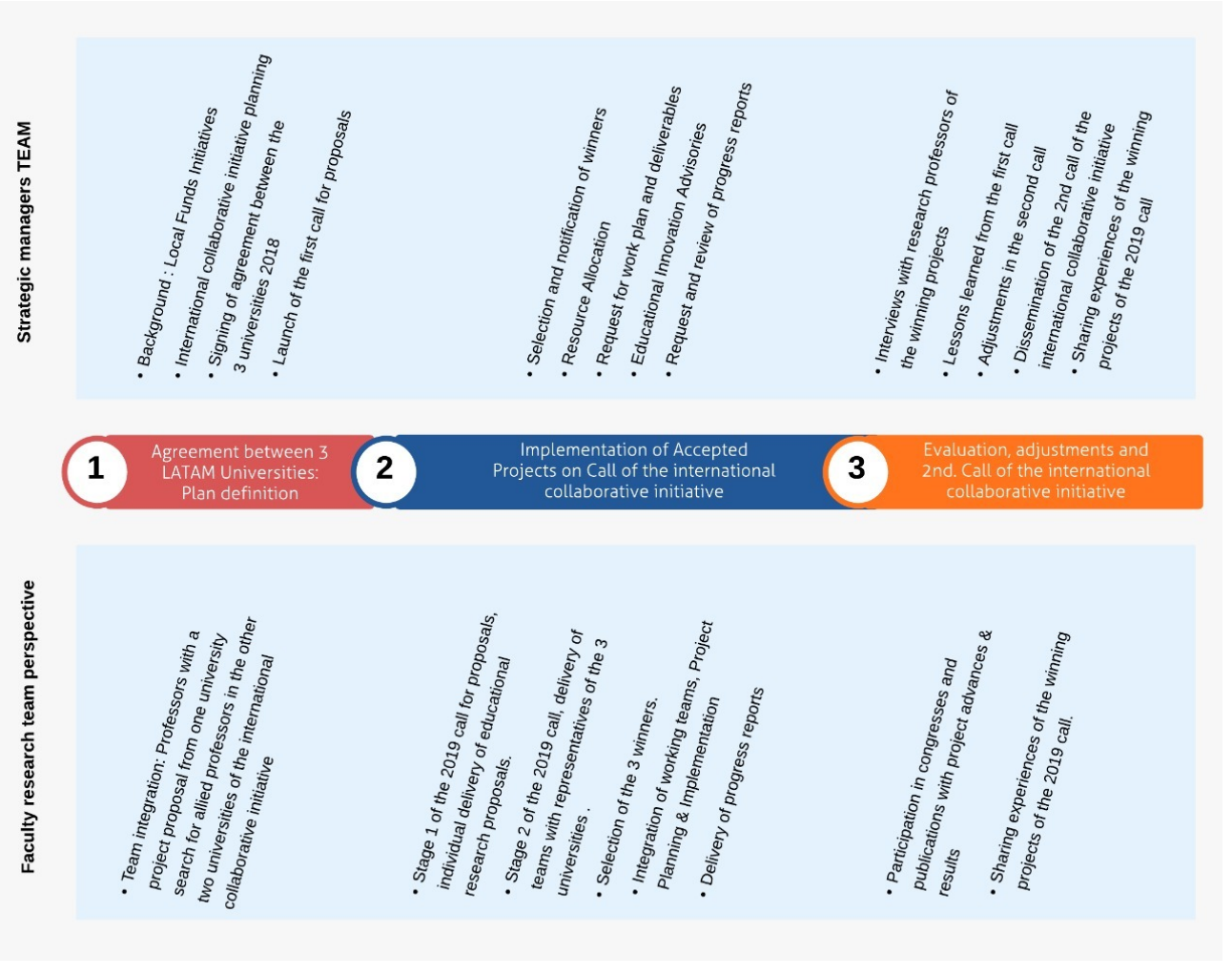

Figure 1: Roadmap Study Case

of them. For university 1 , several work teams are integrated considering several campuses: for the development of the educational innovation resources, for the development of the academic activities that will use the innovative resources, for the implementation of the academic activities and the evaluation, documentation and publications team. In the case of Universities 2 and 3, two teams are integrated: the professors who design, implement, evaluate and document, and the team that develops the educational innovation resource.

- Complementary strengths: some of the participating universities have stronger research backgrounds while others have stronger educational innovation backgrounds. It was an important learning to recognize and leverage these complementary strengths to improve the project [7].

- Finally, the Success assessment for the awarded projects are: Growth and strengthening of research networks [5], enhanced students educational experience [14-16], and publications per project.

\section{CONCLUSIONS}

As reported in the education literature, cooperation between universities takes them out of their comfort zone creating a tension which could be managed to produce significant positive pedagogical results. In our case, collaboration has generated significant results such as increased creativity as a result of the continuous dialogue between researchers, interdisciplinary participation, and the challenge of using new technologies to promote learning. A cooperative culture is essential to obtain positive results in this type of ventures between universities located in different regions and countries.

The involvement of universities from different countries contributes to a greater experience in education because it provides an exchange of cultural ideas. Although these universities are from Latin America, the culture and reality in each of their countries is different in some aspects, which clearly benefits the students and enriches their vision of the world. The technological new resources allow to see the interaction between the reality and the lessons learned in class, so the association of the contents generates a greatest impact, and it is highly valued by students. The cooperation among universities enriches the perspective of the application of activities. This is because through brainstorming several possibilities which lead to activities with greater potential are identified in benefit of students. The process followed by the three universities was successful in generating an understanding among researchers about educational practices that were collectively discussed, agreed and carried out with academic rigor. Faculty commitment, as well as the trust placed on them by the universities' administrative staff is essential for this type of project to be successful. This is especially true in times of crisis and continuous change, such as those that have been faced in the wake of the Covid-19 pandemic. In our case, flexibility that the project has had, thanks to the funding granted by the universities to which the researchers belong, has also contributed to the success of interuniversity collaboration. 
Table 2: Strategic Manager Team interviews results

\begin{tabular}{|c|c|c|c|}
\hline Topics & University 1 & University 2 & University 3 \\
\hline $\begin{array}{l}\text { Universities' purposes to create } \\
\text { International Collaborative } \\
\text { Initiative[4] }\end{array}$ & $\begin{array}{l}\text { Maximize what each university } \\
\text { does in terms of educational } \\
\text { innovation and research }\end{array}$ & $\begin{array}{l}\text { Foster a culture of } \\
\text { educational innovation } \\
\text { and strengthen } \\
\text { collaboration networks } \\
\text { between the universities }\end{array}$ & $\begin{array}{l}\text { Promote educational innovation and } \\
\text { collaborative application of } \\
\text { knowledge. }\end{array}$ \\
\hline Faculty participation & Increase with time & $\begin{array}{l}\text { Stronger participation } \\
\text { from University } 1\end{array}$ & $\begin{array}{l}\text { Great participation and interest from } \\
\text { professors }\end{array}$ \\
\hline Research's progress observation & $\begin{array}{l}2 / 3 \text { projects show progress, one } \\
\text { projects changes purpose }\end{array}$ & $\begin{array}{l}\text { Pandemic strongly hit the } \\
\text { projects, forcing many } \\
\text { changes }\end{array}$ & $\begin{array}{l}\text { Pandemic affected the projects, but all } \\
\text { resumed and updated work plans. }\end{array}$ \\
\hline $\begin{array}{l}\text { Parameters to measure the } \\
\text { success of this initiative }\end{array}$ & $\begin{array}{l}\text { \#publications, } \% \text { of external } \\
\text { funds; linkage with industry; } \\
\text { impact level }\end{array}$ & $\begin{array}{l}\text { There are no explicit } \\
\text { indicators but the } \\
\text { qualitative expectations } \\
\text { include a stronger culture } \\
\text { of educational innovation, } \\
\text { and stronger and closer } \\
\text { collaboration networks. }\end{array}$ & $\begin{array}{l}\text { \# proposals submitted; results of the } \\
\text { projects, achievement of proposed } \\
\text { objectives and the impact. These are } \\
\text { expected to be seeds for future } \\
\text { collaborations. }\end{array}$ \\
\hline $\begin{array}{l}\text { Benchmarks with other } \\
\text { educational innovation research } \\
\text { initiative (internal) }\end{array}$ & $\begin{array}{l}\text { Local funds (institutional } \\
\text { version) }\end{array}$ & Fondedoc; Innovadoc & \\
\hline $\begin{array}{l}\text { Benchmarks with other } \\
\text { educational innovation research } \\
\text { (external) }\end{array}$ & $\begin{array}{l}\text { Not with the same } \\
\text { characteristics. }\end{array}$ & $\begin{array}{l}\text { Not with the same } \\
\text { characteristics. }\end{array}$ & Not with the same characteristics. \\
\hline $\begin{array}{l}\text { Challenges of the international } \\
\text { partnership [9] }\end{array}$ & $\begin{array}{l}\text { Differences in the structure of } \\
\text { each university, different } \\
\text { academic terms (calendar), } \\
\text { different perspectives on } \\
\text { educational innovation }\end{array}$ & $\begin{array}{l}\text { Different timings at each } \\
\text { university, money } \\
\text { exchanges, and internal } \\
\text { bureaucracies }\end{array}$ & $\begin{array}{l}\text { The non-transferring money } \\
\text { agreement between universities may } \\
\text { be limiting. Support the formation of } \\
\text { the teaching teams of the three } \\
\text { universities. }\end{array}$ \\
\hline Lesson Learned & $\begin{array}{l}\text { To carry out the call with a } \\
\text { single phase for registration. } \\
\text { Support communication } \\
\text { between professors of the } \\
\text { universities for the integration } \\
\text { of teams. Focus on current } \\
\text { needs such as technology in } \\
\text { distance format. }\end{array}$ & $\begin{array}{l}\text { Team leadership, use of } \\
\text { collaboration technologies, } \\
\text { need for flexibility and } \\
\text { patience }\end{array}$ & $\begin{array}{l}\text { Large variety of research products is } \\
\text { needed; redesign of communication } \\
\text { mechanisms and participation } \\
\text { invitations needed. }\end{array}$ \\
\hline
\end{tabular}

We believe that this type of collaboration between universities becomes even more important in times of rapid change, because thanks to collaboration, pedagogical materials can be developed more quickly and before new changes occur. Joint efforts enable economies of scale and economies of diversity that benefit both educators and students. For collaboration to be effective, various soft skills of researchers are required, among which teamwork skills, leadership, communication competencies, critical thinking, adaptability, and problem solving stand out. In our case, among the factors cited by [7] for effective collaboration between universities, the existence of common interests, trust, involvement mechanisms, role of personality, professionalism, and the willingness to overcome any barriers that impede collaboration were particularly beneficial. The participation of different disciplines has made the process more challenging, but at the same time, more enriching. Ideas from other fields have been an inspiration to others.

\section{ACKNOWLEDGMENTS}

The authors would like to acknowledge the full support of the School of Engineering and Sciences and Novus Triada Team. The authors would like to acknowledge the financial and the technical support of Writing Lab, Institute for the Future of Education, Tecnologico de Monterrey, Mexico, in the production of this work

\section{REFERENCES}

[1] Marcela Hernandez-de-Menendez, Antonio Vallejo, Juan Carlos Tudón, Diana Hernández, and Rubén Morales-Menéndez. 2019. "Active learning in engineering education. A review of fundamentals, best practices and experiences", Int f Interact Des Manuf 13, 909-922. https://doi.org/10.1007/s12008-019-00557-8

[2] Lorelli Nowell, Swati Dhingra, Kimberly Andrews, Julia Gospodinov, Cathy Liu, and K. Alix Hayden. 2020. Grand Challenges as Educational Innovations in Higher Education: A Scoping Review of the Literature. Education Research International, 1-39. https://doi.org/10.1155/2020/6653575

[3] Jonathan Adams. 2013. Collaborations: The fourth age of research. Nature, 497(7451) pp. 557-560 https://doi.org/10.1038/497557a 
[4] Caroline S. Wagner. 2006. International Collaboration in Science and Technology: Promises and Pitfalls. Science and Technology Policy for Development, Dialogues at the Interface, edited by L. Box and R. Engelhard. London: Anthem Press.

[5] Karen White. 2019. Publication Output: U.S. Trends and International Comparisons. Science and Engineering Indicators 2020. Alexandria, VA: NSF, NSB Retrieved from https://ncses.nsf.gov/pubs/nsb20206/

[6] Caroline S. Wagner, Travis A. Whetsell, and Satyam Mukherjee. 2019. International research collaboration: Novelty, conventionality, and atypicality in knowledge recombination. Research Policy, 48(5), 1260-1270

[7] Anne Valk and Mairit Kratovitš. 2021. We collaborate with everyone, but with some more than others: evidence of stakeholder collaboration among internal security professional higher education institutions. Empirical Res Voc Ed Train 13, 4 https://doi.org/10.1186/s40461-021-00110-6

[8] Herbert H. Tsang, Alice Schmidt Hanbidge, and Tony Tin. 2018. Experiential Learning through Inter-University Collaboration Research Project in Academic Integrity. WCCCE 2018 Proceedings of the 23rd Western Canadian Conference on Computing Education, Victoria, BC, Canada, 1-6. https://doi.org/10.1145/3209635. 3209645

[9] Kirstin R. W. Matthews, Erin Yang, Steven W. Lewis, Brandon R. Vaidyanathan and Monica Gorman. 2020. International scientific collaborative activities and barriers to them in eight societies. Accountability in Research, 27(8) 477-495, https://doi.org/10.1080/08989621.2020.1774373

[10] David Garza. 2019. Latin America University Rankings 2019: Let's challenge students. Times Higher Education site. Tecnologico de Monterrey, Mexico. https://www.timeshighereducation.com/opinion/latin-america-universityrankings-2019-lets-challenge-students

[11] Marcela Hernandez-de-Menendez, Carlos A. Escobar Díaz, and Ruben Morales Menendez. 2020. Engineering education for smart 4.0 technology: a review. Int J Interact Des Manuf 14, 789-803. https://doi.org/10.1007/s12008-020-00672-x

[12] Patricia Caratozzolo, Gabriela Sirkis, Clara Piloto, and Marc Correa. 2020. Skills Obsolescence and Education Global Risks in the Fourth Industrial Revolution. 2020 IFEES World Engineering Education Forum - Global Engineering Deans Council (WEEF-GEDC), Cape Town, South Africa. pp. 1-5. doi: 10.1109/WEEFGEDC49885.2020.9293687.

[13] Jorge Membrillo-Hernández, Elsy G. Molina-Solís, Vianney Lara-Prieto, and Rebeca M. García-García. 2020. Designing the Curriculum for the 4IR: Working the Case of Biology and Sustainable Development in Bioengineering Courses. In: Auer M., Hortsch H., Sethakul P. (eds) The Impact of the 4th Industrial Revolution on Engineering Education. ICL 2019. Advances in Intelligent Systems and Computing, vol 1135. Springer, Cham. https://doi.org/10.1007/978-3-030-40271-6 31
[14] Martha Elena Núñez, Daniel Savedra Olivo, Miguel X. Rodriguez-Paz, Roberto Pablo Martínez Lozano, and Robert Huddleston. 2020. Promoting Sustainable Development Education through Competency-based Education Supported by Online Resources. In 2020 The 4th International Conference on Digital Technology in Education (ICDTE 2020), September 15- 17, 2020, Busan, Republic of Korea. ACM, New York, NY, USA, 8 pages. https://doi.org/10.1145/3429630.3429650

[15] Jorge A. Gonzalez-Mendivil, Miguel X. Rodriguez-Paz, Eduardo CaballeroMontes, and Israel Zamora-Hernandez. 2020. Virtual Reality Environments as a Strategy to Improve Processes Productivity. In 2020 12th International Conference on Education Technology and Computers (ICETC'20), October 23-26, 2020, London, United Kingdom. ACM, New York, NY, USA, 4 pages. https://doi.org/10.1145/ 3436756.3437039

[16] Benjamin Sanchez and Miguel X. Rodriguez-Paz. 2020. Using BIM as a collaborative platform to improve e-learning in civil engineering. In 2020 12th International Conference on Education Technology and Computers (ICETC'20), October 23-26, 2020, London, United Kingdom. ACM, New York, NY, USA, 6 pages. https://doi.org/10.1145/3436756.3437015

[17] B. Yazan, "Three approaches to case study methods in education: Yin, Merriam, and stake," The Qualitative Report, vol. 20, no. 2, pp. 134-152, 2015.

[18] R. E. Stake, Qualitative research: Studying how things work. New York, NY: Guilford Publications, 2010.

[19] Nerida Hyett, Amanda Kenny, and Virginia Dickson-Swift. 2014. Methodology or method? A critical review of qualitative case study reports. Int J Qualitative Studies on Health and Well-being, 9:1, DOI: 10.3402/qhw.v9.23606

[20] Ana Cecilia Salgado Lévano. 2007. Investigación Cualitativa: diseños, evaluación del rigor metodológico y retos. Liberabit. 13(13), 71-78.

[21] QS Latin America University Rankings 2021. Retrieved from https: //www.topuniversities.com/university-rankings/latin-american-universityrankings/2021

[22] William C. Adams. 2015. Conducting Semi-Structured Interviews. In Handbook of Practical Program Evaluation (eds K.E. Newcomer, H.P. Hatry and J.S. Wholey). https://doi.org/10.1002/9781119171386.ch19

[23] Fondo Novus para la innovación educativa. Retrieved from https://novus.itesm. $\mathrm{mx} /$

[24] La Triada: Una alianza en la educación superior y la investigación para la prosperidad de América Latina. Retrieved from https://latriada.tec.mx/es/inicio

[25] M. Ileana Ruiz-Cantisani, Fabiola del Carmen Lima-Sagui, Nancy Aceves-Campos, Ricardo Ipiña-Sifuentes, and Elvira G. Rincón Flores. 2020. Virtual Reality as a tool for active learning and student engagement: industrial engineering experience. 2020 IEEE Global Engineering Education Conference (EDUCON), Porto, Portugal. pp.1031-1037. doi: 10.1109/EDUCON45650.2020.9125225 